\title{
Crónica de la prensa salvadoreña: imaginarios que migran
}

Amparo Marroquín Parducci

Universidad Centroamericana José Simeón Cañas, San Salvador. Correo electrónico: amparo@iteso.mx

Recibido: abril de 2008 / Aceptado: junio de 2008

EL ARTÍCULO PRESENTA UN ESTUDIO DE LAS NARRATIVAS QUE LA PRENSA escrita ha venido construyendo en El Salvador en torno al fenómeno de la migración. Se argumenta que a través del tema de la migración se construye una poética de nación imaginada, y conjuntamente, se da la construcción de las alteridades que desde el discurso oficial se han mantenido vigentes.

Palabras clave: migración / narrativas / prensa escrita / cultura

\section{Introducción: de medios y migraciones}

\begin{abstract}
Se suele representar la inmigración como si fuera una foto fija, sin perspectiva histórica o sociológica. Se olvidan frecuentemente los lazos existentes en el pasado, y se representa una alteridad desvinculada de nuestra historia. Como son los “otros”, no forman parte de nuestra historia. Así se producen curiosos ejercicios de amnesia histórica. También se olvida que sociológicamente los migrantes son muy dispares. A aquellos que no cumplen el estereotipo se les suele considerar una excepción.
\end{abstract}

Miquel Rodrigo Alsina (2003)

El investigador español Miquel Rodrigo Alsina lo dice con una imagen clara. Solemos representarnos el fenómeno de la migración con una serie de fotos fijas. Un álbum familiar que nos cuenta de las remesas, la familia que se queda y su influencia en las dinámicas locales. Olvidamos en ciertos momentos que la migración debe ser historizada. El Informe de Desarrollo Humano (2005) del PNUD habla de tres etapas sucesivas de la migración salvadoreña que inician en 1920, otros historiadores sitúan la lectura sobre la migración incluso más atrás en el tiempo, algunos analistas más dirán que siempre ha acompañado a los grupos humanos.

El presente estudio se aproximará a los discursos que la prensa escrita de El Salvador ha elaborado en relación con el fenómeno de la migración en los últimos veinte años y la manera como los salvadoreños nos situamos frente a dichos discursos. El punto de partida es la idea de la comunicación como un espacio estratégico desde el cual es posible pensar lo que somos, las contradicciones y los dinamismos que nos mueven. Al aproximarnos a los discursos mediáticos, podemos saber qué sucede con nuestras sociedades que, a decir de Jesús Martín Barbero (1998), se encuentran a medio camino entre el subdesarrollo acelerado y la modernización compulsiva. 
En El Salvador existe ya un número significativo de estudios que abordan el tema de la migración desde distintos ámbitos, sin embargo, el territorio de la cultura sigue siendo marginal en esta reflexión. Muy poco se ha elaborado en relación con los discursos sociales que construyen ciertas representaciones sobre la migración en la sociedad. Tal y como menciona Yúdice (2006:107), "la cultura como un estilo de vida integral crea lo que Butler llama un horizonte de inteligibilidad, dentro del cual se dan luchas interpretativas mediante prácticas más o menos institucionalizadas para establecer hegemonía”. Los medios de comunicación no sólo presentan noticias y dan visibilidad a discursos y actores, además de ello los re-presentan. Dan prioridad a ciertas imágenes en detrimento de otras, es por ello que hablamos de un imaginario, de una representación que desde los medios de comunicación ha visibilizado el fenómeno de la migración y lo ha asociado con ciertos discursos e imágenes que en su momento han sido convenientes para ciertos grupos en el poder. De nuevo para decirlo con Yúdice (2006:107) "la cultura, además de ser trascendencia, enaltecimiento e identidad compartida, es también delimitación que respalda jerarquías y relaciones de poder".

El objetivo de esta reflexión es conocer qué se ha escrito sobre la migración en la sociedad salvadoreña y cómo se ha vivido este discurso de los medios, qué postura se ha tomado en relación con los múltiples y complejos temas que de ella se desprenden. Los medios de comunicación son uno de los espacios más importantes de negociación de representaciones. El Latinobarómetro (2006) muestra cómo siete de cada diez personas confían en la radio y la televisión, y cuatro de cada diez en la prensa escrita. En el caso salvadoreño, después de la Iglesia, los medios de comunicación suelen presentarse como la institución en la que más confían las personas. ${ }^{1}$ Existen muchas percepciones que los investigadores han intentado matizar, como que la emigración "es una mala influencia para la familia" (Lungo y Kandel, 2002:918), que las familias que reciben remesas "malgastan en consumos superfluos las remesas" (Andrade-Eekhoff, 2003:21) o que "los deportados son la causa del aumento de la violencia de las pandillas" (PNUD, 2005:315 en adelante). En este estudio me acercaré a este discurso mediático a lo largo de veinte años e intentaré mostrar qué ha cambiado y qué se mantiene del mismo.

En el estudio sobre los medios de comunicación y sus discursos, el tema de los efectos que éstos tienen sobre las personas, se ha discutido desde muchas teorías y enfoques. De hecho, algunas teorías, se han aproximado a elaborar en qué medida el discurso de los medios afecta la manera como las personas configuran sus propias reflexiones. También se ha discutido en qué medida las noticias responden a intereses institucionales, a lógicas de producción o se establecen desde mediaciones culturales y son, desde ahí, recibidas por los consumidores. ${ }^{2}$ No se pretende en este estudio determinar estas relaciones cuya complejidad es difícil de abarcar. Sin embargo, sí resulta importante anotar lo que señaló en su momento el historiador Roger Chartier sobre las prácticas de lectura: "La representación es un objeto de lucha entre la representación propuesta y la impuesta" (Chartier en Ceballos y Alba, 2003:13). En este sentido, importa tanto lo que los medios proponen sobre la migración, como lo que desde el colectivo termina imponiéndose. Muchas veces lo que se impone no es necesariamente lo que los periodistas buscaron decir, en otras ocasiones, mediaciones y presiones que no tienen directamente que ver con la estructura del medio llevaron a que una manera de interpretar la migración domine el discurso. 
Los expertos insisten que en los medios de comunicación no sólo se ponen en común acontecimientos, sino sobre todo, se negocian significados. Los salvadoreños, por ejemplo, tienen la percepción de que en el país la mayoría de los hechos delictivos y violentos son producto de las riñas entre pandillas, cuando ésta es una hipótesis policial que aún no ha podido ser probada (Cruz y Santacruz, 2005). Lo que muchos ciudadanos piensan sobre los jóvenes que pertenecen a pandillas es posible encontrarlo reproducido en las noticias que a diario se transmiten. En los productos mediáticos, en los noticieros en radio y televisión, en las notas y artículos de la prensa escrita e internet se pueden encontrar los gustos y los miedos, las alegrías y las represiones que se viven dentro de una sociedad y desde una cultura.

Los medios de comunicación re-crean, negocian sus sentidos, exaltan un elemento mientras hacen que otro más sea olvidado. Al reflexionar sobre los medios de comunicación y las migraciones, una primera constatación es en qué medida estos medios visibilizan la realidad de la migración. ¿Cuánto y qué muestran los medios de comunicación? El aumento de la información sobre migraciones es evidente en los últimos años. Y no sólo es la nota informativa.

La prensa escrita ha multiplicado la información sobre migraciones. Hasta ahora, la institución periodística que en el país ha sabido unificar las distintas transformaciones tecnológicas para presentar un periodismo más complejo y completo en relación con la migración es el equipo de La Prensa Gráfica. Además de tener circulación diaria en el territorio nacional, el periódico se vende desde 2002 de manera periódica en las cinco ciudades de Estados Unidos con mayor porcentaje de población salvadoreña: Los Ángeles, San Francisco, Houston, Nueva York y Washington. En diciembre de 2004, el más reciente proyecto multimedia fue una alianza con dos cadenas nacionales de radio y una internacional: Univisión radio. Este matutino cuenta, además, con una sección diaria en el medio impreso desde 2000: Departamento 15. La página en internet de dicha sección, (http://www.laprensagrafica.com/dpt15/), ofrece información adicional que no aparece en la edición impresa, como la ubicación de los consulados salvadoreños en México y Estados Unidos o los datos de contacto de las organizaciones de salvadoreños en el mundo. Una alianza televisiva de Departamento 15 con la cadena Univisión, canal 34 en Los Ángeles, ofrece reportajes que pueden ser vistos en la página web.

Justamente de la prensa escrita me ocuparé de manera detallada, si bien el medio de mayor penetración entre las audiencias sigue siendo la televisión, la prensa en El Salvador tiene una audiencia cautiva que, algunos calculan, llega al millón de personas. ${ }^{3}$ Tiene además, al igual que el resto de los medios, un efecto multiplicador a través de comentarios y discusiones que se establecen, va de mano en mano y es muy utilizado por líderes de opinión en espacios que van desde los comunitarios hasta los nacionales. Las noticias tienen además la facilidad de encontrarse archivadas en hemerotecas e institutos de investigación.

Este texto se divide en tres apartados. El primero pretende hacer una breve crónica de la metodología utilizada en el estudio, y algunas reflexiones que surgen de la misma. El siguiente apartado trabaja de manera extensa cuatro grandes imaginarios que la prensa escrita salvadoreña ofrece desde las distintas páginas de los informativos. Un apartado 
más se aproximará a los itinerarios de la recepción. Discursos que algunos salvadoreños han manifestado sobre la prensa escrita y la manera como este planteamiento estandariza una historia y maneja en su estructura profunda cierto tipo de categorías. Finalmente desarrollaré unas conclusiones iniciales que intentan ser más bien una provocación para continuar con la discusión. Inicio, pues, la reflexión, desde una relectura del método.

\section{Materiales y métodos}

Para entender cómo en nuestra sociedad salvadoreña se ha configurado una imagen sobre la migración y sobre aquellos que han tenido que salir fuera del país, se ha rastreado lo que la prensa escrita ha contado en relación con el tema. Esta búsqueda abarca dos décadas, desde 1985, mientras se desarrollaba el conflicto armado, hasta el año 2004, cuando las discusiones sobre la problemática del país pasaban por otras temáticas más globales y múltiples. La falta de archivos sistematizados tanto en radio como en televisión vuelve casi imposible un estudio de este tipo en dichos medios. Le prensa escrita, por su formato y la permanencia de su lenguaje, se presta mucho más a un trabajo diacrónico.

Debido a la falta de estudios sobre los medios de comunicación y su tratamiento sobre el tema de la migración, en El Salvador hay pocas posibilidades de comparación y de profundización de estas primeras conclusiones. Se revisaron los periódicos cada cinco años: 1985, 1990, 1995, 2000 y 2004. Ninguno de los periódicos se revisó de manera digital en esta etapa, todos fueron rastreados en hemerotecas y bibliotecas con colecciones especiales. En total, el análisis tiene como base el estudio de 667 noticias publicadas en los cuatro periódicos mencionados. A partir del año 2000 se han añadido algunas notas que se encuentran fuera de la periodización establecida pero que permiten ilustrar aspectos fundamentales que no aparecieron de forma clara dentro de la muestra. Este es el caso del suplemento especial sobre los viajeros, publicado en febrero de 2004 en La Prensa Gráfica o algunas notas de 2005 y 2006 que serán citadas a lo largo del trabajo.

Como las noticias sobre el tema cada vez son más, se optó por recolectar las notas de un mes, cada cuatro meses del año: abril, agosto y diciembre. Por un lado, abril fue un mes en el que, en algunos años, se celebró la semana santa, y en otros no hubo una fiesta religiosa 0 política que convocara a los migrantes del exterior. Agosto continúa siendo un mes en el que los salvadoreños celebran la fiesta de "La Transfiguración", conocida por los capitalinos como "la bajada", y por otros como "la fiesta del Divino Salvador"; además, es todavía un mes de verano y vacación en muchos países del norte, por lo que la afluencia de migrantes y las noticias sobre las celebraciones en otros países cobran protagonismo. Finalmente, diciembre, que en un inicio se pensó como la época de mayor afluencia y en los últimos años estudiados se mostró como "un mes más" que acoge en el aeropuerto a miles de emigrantes que vuelven a pasar unos días en sus lugares de origen.

El estudio es cualitativo. Su preocupación fundamental es rastrear discursos. En este sentido se utilizará como apoyo la cuantificación de las noticias, pero no será desde una representatividad estadística, sino más bien desde criterios de diversidad como se trabajarán las conclusiones. Aún así, esta cuantificación de las notas publicadas me ha permitido en algunos casos iniciar una comparación temporal. Para el trabajo se recogieron todas las 
notas sobre migración que fueron publicadas en cuatro periódicos: La Prensa Gráfica (LPG), El Diario de Hoy (EDH), Diario El Mundo (EM) y Diario CoLatino (CL).

Los críticos de la metodología de análisis discursivo piden con urgencia ir hacia las audiencias que reciben el mensaje. Por ello, en la búsqueda de una aproximación más compleja, se realizó un sondeo durante los meses de octubre y noviembre de 2005 a personas que viven en distintos municipios del país para conocer qué opinan sobre la manera como se abordan las noticias sobre migración en los medios de comunicación -particularmente en la prensa escrita- de El Salvador. El sondeo se llevó a cabo como parte de un trabajo de campo mayor que será motivo de otra discusión posterior: una observación de las fiestas patronales y los procesos de migración de las localidades. ${ }^{4}$ Los comentarios ilustran mejor qué es lo que las y los salvadoreños interpretan sobre los relatos que el periodismo maneja.

En relación con el discurso de la prensa escrita, una constatación esperada fue documentar cómo la cantidad de noticias aumentó con los años. La necesidad de la población de informarse y discutir sus dudas sobre cuestiones legales, los peligros en el viaje, la información sobre sus seres queridos, ha hecho que en todos los medios, como se mencionó con anterioridad, se multipliquen los espacios semanales o los reportajes especiales dedicados a solventar las inquietudes de sus audiencias. Con la llegada de las nuevas tecnologías, especialmente con la aparición y difusión de internet desde 1995, las noticias sobre migración no sólo se leyeron en el país, sino también en los distintos países donde los salvadoreños han migrado.

El cuadro 1 muestra el crecimiento en la cantidad de noticias. Un dato significativo es que los dos matutinos con mayor difusión, La Prensa Gráfica y El Diario de Hoy, asignaron espacios importantes para trabajar exclusivamente el tema de los migrantes.

Cuadro 1. Número de notas encontradas sobre el tema migración y migrantes

\begin{tabular}{|c|c|c|c|c|c|}
\hline & LPG & EDH & EM & CL & Total por año \\
\hline $\mathbf{1 9 8 5}$ & 9 & 8 & 1 & 1 & 19 \\
\hline $\mathbf{1 9 9 0}$ & 20 & 28 & 15 & 6 & 69 \\
\hline $\mathbf{1 9 9 5}$ & 41 & 23 & 12 & 7 & 83 \\
\hline $\mathbf{2 0 0 0}$ & 86 & 58 & 17 & 22 & 183 \\
\hline $\mathbf{2 0 0 4}$ & 157 & 139 & 17 & 10 & 323 \\
\hline Total & 313 & 256 & 62 & 46 & $\mathbf{6 7 7}$ \\
\hline
\end{tabular}

Fuente: Elaboración propia.

LPG inició en el año 2000 la sección Departamento 15 que al principio apareció como una sección noticiosa que servía como espacio de contacto con los habitantes repartidos en el espacio transnacional: el decimoquinto departamento del país. El 4 de julio de 2003 pasó a ser una sección diaria con noticias de lunes a sábado. Por su parte, EDH inició en 2002 el proyecto Elsalvador.com, distinto del sitio web que lleva el mismo nombre. El objetivo del proyecto era publicar en la edición impresa noticias sobre la migración, aunque se 
mantenía una información mucho mayor en la página Web. A lo largo de los últimos tres años el proyecto ha llegado a ser una sección diaria con corresponsales en Estados Unidos y México. Es necesario notar que periódicos como El Mundo y Co Latino aparecen con frecuencias de noticias sobre migración bastante inferiores. Sin embargo, si consideramos el promedio de páginas de sus ediciones diarias, en realidad también le han otorgando un espacio significativo al tema. Frente a La Prensa Gráfica y El Diario de Hoy, cuyas ediciones suelen tener un promedio de 110 páginas, las ediciones de El Mundo mantienen 45 páginas y las de CoLatino 20 páginas en promedio. ${ }^{5}$

Al acercarnos a la información sobre migración en la prensa escrita surgen varias preguntas. ¿Qué relatos de identidad de los salvadoreños privilegia la prensa al hablar sobre la migración? ¿Cuáles son las imágenes y los relatos que más se anclan en los lectores salvadoreños? ¿Hay algún tipo de imagen sobre el migrante que destaque?

En la presente revisión se ha podido constatar que la prensa escrita del país mantiene un discurso diverso en el tratamiento del tema de la migración. La temática migrante es abordada desde distintas perspectivas, pero ello no implica necesariamente complejidad. Los discursos se mantienen más bien reproduciendo estereotipos y lugares comunes. En algunos casos, se encontró ambigüedad en la postura editorial; en otros, se reflejaron matices por el abordaje particular de cada periodista. La apuesta de los medios impresos salvadoreños, en otros casos, se diluye en medio de una saturación de información que no logra mantener un discurso complejo y respetuoso sobre la realidad migrante. En algunos casos, sin embargo, se documentó en la muestra notas que intentan mostrar la densidad del tema.

Para comprender mejor estas afirmaciones, el siguiente apartado explora las temáticas y las imágenes que la prensa salvadoreña va configurando sobre un tema que tiene muchas aristas, y su particular diversidad.

\section{Imaginarios que migran: compatriota vrs. deportado}

Cuatro grandes relatos se han encontrado en la información de prensa en torno a la migración: uno político, otro económico, otro más cultural y finalmente uno social. Estos cuatro relatos muestran enfoques diferenciados en el tiempo. En el relato político, las identidades van desde los refugiados políticos, hasta los pandilleros deportados; en el económico, aparecen los migrantes que envían remesas, los viajeros y los empresarios exitosos gracias a la migración tanto en el país como en el extranjero; en el relato cultural se recoge el éxito de los salvadoreños en otros países, y vivencias como las fiestas patronales, el lenguaje, la comida y las costumbres salvadoreñas en este país ampliado que se encuentra en muchas naciones; en el relato social se presenta el largo camino recorrido antes de llegar a la tierra prometida, los salvadoreños que fracasan en el camino y los responsables de ese fracaso (policía, pandilleros o coyotes inescrupulosos).

En la muestra que se utilizó para el estudio se encontraron dos propuestas en relación con el migrante. La primera es la que privilegia este término de com-patriota que connota un sentido de inclusión en el cual todos compartimos la misma patria y que amplía hacia fuera 
la noción de territorio. La segunda propuesta representa al migrante como alguien lejano, incluso a veces como alguien no querido cuando es deportado al territorio salvadoreño.

Algunas notas presentan a los migrantes como sujetos de derecho y en otras se les estereotipa de tal forma que se puede propiciar la marginación. Para comprender mejor estas afirmaciones se desarrollan a continuación cuatro temáticas o relatos de la prensa salvadoreña sobre el tema.

\section{3.a. Lo político: del refugiado que huye al marero que vuelve}

Durante la guerra la discusión más grande en la muestra de periódicos fue definir cuál era el estatus de los salvadoreños que salieron fuera del país. En 1985 la discusión se dividía en dos argumentos correspondientes a dos posturas políticas: ¿los salvadoreños eran refugiados que sufrían la persecución debido a sus ideas y adscripciones políticas o más bien migraron por razones económicas y debían ser tratados como cualquier ilegal que llegaba a Estados Unidos en busca de un trabajo? Los medios se volvieron un espacio de discusión. Las posturas fueron diversas: por un lado, el discurso oficial de Estados Unidos fue recogido por las noticias. En estas notas se presentaban declaraciones de altos funcionarios norteamericanos que insistían en no reconocer a las personas que venían de El Salvador un estatuto de refugiado. Por el otro, la opinión pública salvadoreña, tanto desde un discurso más crítico como desde una postura más conservadora, no ponía en duda la problemática de guerra en el país y el hecho que muchos salvadoreños y salvadoreñas tuvieran que salir huyendo, perseguidos y agobiados por la violencia. Aún así, no hubo una confrontación abierta sobre el tema ni se pudieron rastrear notas que hicieran un análisis más detallado.

Lo que más se encontró fueron algunas reflexiones. En la mayoría de los casos se toma una clara distancia del discurso estadounidense, insistiendo en que la población salvadoreña es víctima de la guerra, lo que diverge son las causas de esta victimización, para unos será la guerrilla, para otros el ejército y los grupos paramilitares.

Ciertas notas muestran una clara preocupación por que no se deporte a los salvadoreños. Algunas noticias incluso citan a organismos internacionales como el Movimiento Santuario que trabaja para que los salvadoreños no sean deportados pues pueden llegar a ser perseguidos políticamente en su país. Aun y cuando estas notas presentan a los salvadoreños como "non gratos", su visión de los mismos suele ser positiva. No hay enjuiciamientos de valor ni toma de distancia con respecto a estos compatriotas.

El relato sobre el refugiado político es protagónico en 1990 y poco a poco va desapareciendo. Después de la firma de los acuerdos de paz, en la muestra de periódicos se encuentran algunas historias puntuales donde estos refugiados políticos llevan una nueva vida o buscan a sus familiares. Se retoma en algunos momentos la discusión sobre los niños desaparecidos y cómo algunos de ellos llegaron a Estados Unidos.

En la muestra, a partir del año de 1995, posterior a la guerra, una serie de notas convierten la imagen del deportado en hegemónica dentro de las noticias sobre el tema de migración. Muchos otros temas quedan relegados en la muestra de ese año. Pero el tratamiento 
es distinto al anterior: aquí no se habla ya de compatriotas, el deportado adquiere una connotación negativa, de amenaza para la seguridad pública. Se vuelve "el otro" del que hay que cuidarse. Si el refugiado político era una realidad salvadoreña, al deportado criminal debería negársele la entrada al país. El problema de este discurso es que en algunos momentos y por el planteamiento del lenguaje, llega a criminalizarse la deportación en el imaginario social. El cuadro 2 muestra la multiplicación de notas relacionadas con aquellos que los medios denominaron "mareros deportados" a partir de 1995.

Cuadro 2. Deportaciones: el problema de las maras

\begin{tabular}{|c|c|c|c|c|c|}
\hline & LPG & EDH & EM & CL & Total por año \\
\hline 1985 & 0 & 0 & 0 & 0 & 0 \\
\hline 1990 & 0 & 0 & 1 & 0 & 1 \\
\hline 1995 & 8 & 6 & 2 & 0 & 16 \\
\hline 2000 & 10 & 15 & 0 & 0 & 25 \\
\hline 2004 & 18 & 9 & 6 & 0 & 33 \\
\hline Total & 36 & 30 & 9 & 0 & 75 \\
\hline
\end{tabular}

Fuente: elaboración propia.

Las caricaturas publicadas en los periódicos matutinos (LPG y EDH) ilustran muy bien este discurso. En el dibujo y sus respectivos textos los caricaturistas ponen en evidencia el discurso hegemónico. Se burlan de aquellos que han sido deportados al país y asumen que todos ellos han regresado "por haber cometido algún crimen" y se ridiculiza a sus familiares. Desde 1995, la imagen del salvadoreño deportado empieza a ser caracterizada de manera peculiar: "los deportados, quienes vestían atuendos flojos, con tatuajes en sus cuerpos y que a simple vista eran identificados como miembros de las ya famosas 'maras' arribaron al aeropuerto de Comalapa ${ }^{6 ”}$ (LPG, 06/04/95).

El discurso que se multiplica crea esta sensación de que los deportados son cada día más y que la mayoría de ellos han sido criminales. Una nota secundaria en LPG, sin embargo, presenta otros datos: "entre agosto y diciembre de 1994, [la DAN registró] el retorno de 259 personas, de las cuales el 90 por ciento fueron expatriadas por haber ingresado ilegalmente a los Estados Unidos y el resto por tráfico, consumo, venta y posesión de droga, especialmente cocaína”.

En estas noticias, la prensa no hace ninguna diferencia entre el consumo y la posesión de drogas y el tráfico o la venta de las mismas. Los diputados de ARENA y el entonces presidente Calderón Sol refuerzan la línea de preocupación. Esto pone en discusión una ley de seguridad ciudadana: "Los antisociales deportados de los Estados Unidos representan una bomba de tiempo que debe ser desactivada con una ley que proteja a la ciudadanía honrada" indicó René Figueroa como diputado del partido de derecha (LPG, 07/04/95). Esta imagen de "bomba de tiempo" será retomada por la prensa escrita y repetida en varias notas. El gobierno de El Salvador inicia una queja formal contra el gobierno de Estados 
Unidos que está deportando salvadoreños, pues, explican los periódicos "es absolutamente inaceptable que cualquier país del mundo exporte reos condenados... atenta contra los derechos personales del resto de salvadoreños que estamos pretendiendo luchar contra la criminalidad" (LPG, 08/04/95). Estos relatos del miedo se mantienen durante los diez años siguientes, como lo muestra la nota publicada en 2005 donde la entradilla explica que "El Salvador [está], preocupado por las deportaciones, ante la falta de un marco legal para detenciones". En esta nota, el ahora ministro de Gobernación, René Figueroa, pide al gobierno de Estados Unidos "que no deporte a todos los pandilleros detenidos en las últimas semanas" (LPG, 03/08/05).

Los pandilleros mantendrán su presencia y no será exclusivamente el discurso relacionado con la migración el que los convertirá en unos "estigmatizados" (Goffman, 1970). Diversos estudios como el de Vasilachis (2004) y el de Martel (2006) muestran cómo los relatos de la prensa escrita presentan a los jóvenes de pandillas con metáforas que remiten claramente al "otro" social. En la muestra de periódicos de los años 2000 y 2004 "las maras" son relacionadas además con los grupos de asaltos que se aprovechan de los migrantes que van en su ruta a la "tierra prometida". Los pandilleros piden dinero, trafican, asesinan, lanzan a sus víctimas a los rieles del tren donde son mutilados. En algunas notas son relacionados con actividades terroristas y con los problemas de la seguridad nacional que a partir de septiembre de 2001 se vuelven prioridad en las agendas de los Estados.

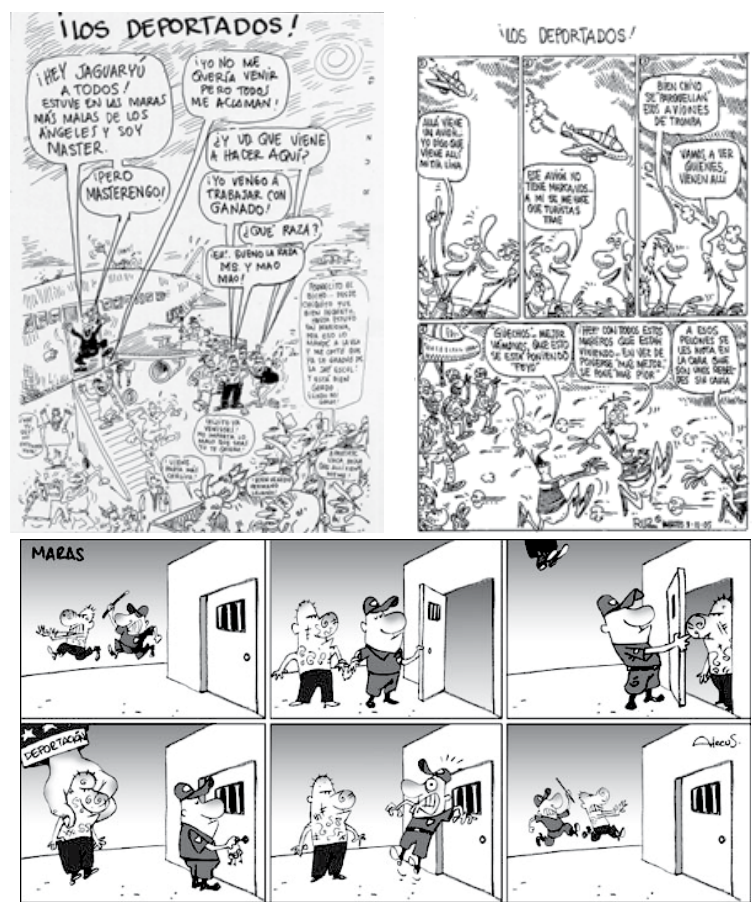

Ilustración 1. Caricaturas

Arriba, izquierda: Los Deportados, Caricatura publicada en LPG en abril de 1995. Once años después (derecha): Los Deportados, Caricatura de EDH del 8 de noviembre de 2005. Abajo: Maras, Caricatura publicada en LPG el 25 de agosto de 2005. 
Esta identidad marcada del deportado marero se ilustra muy bien en las declaraciones recientes de un empresario, que son retomadas en la prensa. La nota retoma los relatos de varios migrantes: "un profesor de Long Island que ayuda a los jóvenes a terminar sus estudios de bachillerato; la de un oficinista que da cursos comunitarios a las policías de Manhattan y Nueva Jersey; o la de una mujer que administra programas dedicados a traer a Estados Unidos a niños salvadoreños que necesitan operaciones que no se pueden realizar en El Salvador. "[Estas historias, afirma el empresario] nos quitan el chuquillo que nos dejan los mareros. Estoy seguro de que esas personas [pandilleros] representan un número ínfimo respecto a todas las personas trabajadoras que viven en esta ciudad y en este país" (LPG, 17/06/05).

\section{3.b. Lo económico: de viajero frecuente a magnate gigante}

Junto con el ámbito político, quizá lo que sucede con la economía sea el relato más discutido y que más ha sido objeto de análisis en nuestro país. Dos son las temáticas que la prensa escrita salvadoreña privilegió sobre la economía migratoria: por un lado, un tema cuantitativo, el crecimiento propiciado por una nueva realidad migrante, crecimiento de la economía, de la población salvadoreña en el mundo, crecimiento de las organizaciones de migrantes; por el otro, un tema más bien simbólico pero con un sustrato económico fundamental: el éxito que muchos salvadoreños alcanzaron al volverse empresarios exitosos en Estados Unidos. La importancia del tema se discute con interés sobre todo después de la firma de los acuerdos de paz, cuando las remesas apuntalan la naciente democracia.

Como se muestra en el cuadro 3, aun y cuando el crecimiento de las remesas cobró particular importancia a partir de 1995, ese año la mayoría de las notas de la muestra no tocaron este tema pues la preocupación por los jóvenes de pandillas, que se ha presentado en el apartado anterior, ocupó buena parte de la agenda.

Cuadro 3: Noticias sobre comunidades y organizaciones de migrantes, sobre el aumento de la población migrante y las remesas

\begin{tabular}{|c|c|c|c|c|c|}
\hline Año & LPG & EDH & EM & CL & Total por año \\
\hline 1985 & 1 & 2 & 0 & 0 & 3 \\
\hline 1990 & 3 & 5 & 2 & 1 & 11 \\
\hline 1995 & 0 & 0 & 0 & 0 & 0 \\
\hline 2000 & 14 & 2 & 0 & 8 & 24 \\
\hline 2004 & 17 & 14 & 1 & 1 & 33 \\
\hline Total & 35 & 23 & 3 & 10 & 71 \\
\hline
\end{tabular}

Fuente: elaboración propia

El crecimiento económico reportado por la migración es documentado por la prensa desde mucho antes que tuviera fin el conflicto armado. Ya en 1985, aparecieron algunas notas sobre el tema, como lo muestra la noticia que informó que: "[El Presidente del Banco Central 
de Reservas, Lic. Alberto Benítez Bonilla, afirmó que] después del café, el otro sector que genera más divisas es la ayuda familiar al exterior" (CL, 05/12/85). En ese momento empezaron a aparecer algunas notas que contaban cómo las comunidades de salvadoreños en el exterior empezaban a crecer tanto en población como en poder adquisitivo, reflejado en parte en las remesas.

En 1990, una noticia retomada de AP mostraba que el incremento de la población hispana hizo que hablar español fuera cada vez más común. Esta constatación se asoció a actividades cotidianas de consumo: una guía telefónica de páginas amarillas en español se publicaba en California; en Nueva York los autobuses y subterráneos tenían publicidad en este idioma; mientras, en Miami, algunas tiendas "llegan al extremo de proclamar 'se habla inglés". Las comunidades de migrantes latinoamericanos empezaron a ser presentadas como poblaciones consumidoras, esto es, con un cierto poder adquisitivo. En 2004, una noticia comenta que la población centroamericana en Estados Unidos "casi se duplicó en la última década, con El Salvador como el principal país emisor de emigrantes”. La nota explica que hay 817 mil compatriotas que residen en EE.UU (LPG, 14/12/04). Como ya se mencionó anteriormente, este término de com-patriota connota el sentido de inclusión, de transnacionalización en la cual todos somos los que compartimos la misma patria. La noción de territorio se amplía hacia fuera, ellos también son parte del Nosotros.

En 1995 empezaron a multiplicarse las noticias sobre salvadoreños exitosos, como aparece en el cuadro 4. A medida que el interés por los migrantes creció, las notas del éxito de "los compatriotas" en tierras extranjeras se diversificaron. Se resaltaron más notas de personas que pasaron "de mojados a empresarios", salvadoreños residentes en el extranjero desde hace ya un largo período y que destacaron en alguna rama del deporte o el arte, escritores que publicaron sus novelas en otros países y su talento fue reconocido, científicos que destacaron, deportistas importantes. Se cubrió también a salvadoreños que residían en el país, pero que fueron llamados por las autoridades de otros países a colaborar, a competir, a montar exposiciones y a poner "en alto" el nombre del país.

Un personaje que destaca en el ámbito económico es el encomendero, conocido también como viajero, que aparece muy poco en las noticias de la muestra, pero que ha sido objeto de un reportaje especial en la revista Enfoques de LPG (01/02/04). En esta nota se presenta a los viajeros como "los nuevos magnates de oriente, los pequeños que se volvieron gigantes", y se explica que hasta antes de las restricciones de seguridad impuestas por el 11 de septiembre, los viajeros podían ganar "casi el salario de un ministro" (el énfasis es mío). Con una serie de testimonios personales se muestra cómo algunos viajeros se han convertido en empresarios y muchos otros dejaron empleos formales para dedicarse de lleno a una "profesión" en la que llevan 25 años.

Aunque la visión sobre los encomenderos suele ser positiva, en algunos casos es posible encontrar un relato más bien negativo, el viajero como un personaje oscuro que se dedica al tráfico ilegal. Tal es el caso de una nota de EDH. Se recuerda que los policías de la División Antinarcóticos "tienen cuidado con los encomenderos, porque usualmente la droga se las ocultan entre los artículos que son enviados a Estados Unidos o Europa" (EDH, 10/07/05). 
En la muestra no se encontraron noticias concretas que plantearan los “costos" económicos del viaje, ni se ahondó en las noticias sobre remesas sobre los costos de transferencia de las mismas, el uso que las familias salvadoreñas daban al dinero recibido o sobre los proyectos de desarrollo que se llevaron a cabo gracias a las remesas colectivas. Es posible que estas noticias hayan entrado en la agenda con periodicidad tan reducida que no llegaron a ser abarcadas en la muestra que se recolectó. Como ya se mencionó al inicio de este apartado, el éxito del migrante conlleva un elemento económico no sólo "monetario", sino también simbólico. Es por ello que la categoría de los salvadoreños exitosos gracias a las migraciones se traslapa con el análisis del discurso cultural.

\section{3.c. Lo cultural: los festejos, el éxito, el retorno}

Una temática que expresamente se ha querido rescatar desde algunas apuestas editoriales de los medios impresos tiene que ver con documentar e informar del éxito que las y los salvadoreños han tenido en el extranjero. La migración exitosa es la temática que más noticias presenta en la muestra; un total de 227 contabilizadas. ${ }^{7}$ En esta muestra, hay una variedad de personajes que aparecen destacados. En general, se hace énfasis en cómo estos "destacados compatriotas" fueron capaces de triunfar en espacios donde muchos otros no lo lograron. Se pone de relieve la fuerza y la tenacidad de los salvadoreños y su capacidad de levantar proyectos, en muchos casos, de la nada.

Ya en 1985 se mostró el renombre de personalidades que pertenecen a grupos socioeconómicos aventajados y el éxito de grupos de becarios de clases menos favorecidas: "La salvadoreña Doris Masear García, de 27 años, presentó como tesis de graduación la construcción del Coliseum de Nueva York como una estructura hexagonal que, según renombrados arquitectos, aventaja en su proyecto a las más importantes firmas de arquitectos norteamericanos" (EDH, 11/08/85); "80 becarios a EE.UU. para técnica vestuario. La industria del vestuario en El Salvador no se quedaría muy atrás de otros países famosos por sus productos de alta costura. Pero, como en todo, siempre hay campos abiertos a la adquisición de nuevas técnicas" (LPG, 15/08/85).

A partir de 1995 se volvieron frecuentes, además, las noticias que cuentan de la muerte de compatriotas migrantes en suelo extranjero. Estos relatos periodísticos mostraron el significativo aumento de la población que se estableció fuera del territorio nacional, pero que conservó los lazos con su país que, en estas historias, esperaba los cuerpos de estos (com)patriotas lejanos. Se evidencia aquí la fuerza simbólica de la repatriación de los cuerpos que aparecerá también en la encuesta dirigida a salvadoreños residentes en Estados Unidos. El cuadro 4 muestra el aumento de las noticias sobre salvadoreños emigrantes exitosos, pero al mismo tiempo, la constancia de este tema a lo largo del estudio. 
Cuadro 4. Sociales: Los migrantes exitosos

\begin{tabular}{|c|c|c|c|c|c|}
\hline & LPG & EDH & EM & CL & Total por año \\
\hline 1985 & 4 & 1 & 0 & 0 & 5 \\
\hline 1990 & 6 & 6 & 7 & 2 & 21 \\
\hline 1995 & 18 & 12 & 5 & 4 & 39 \\
\hline 2000 & 19 & 20 & 12 & 8 & 59 \\
\hline 2004 & 46 & 38 & 6 & 3 & 93 \\
\hline Total & 93 & 77 & 30 & 17 & 217 \\
\hline
\end{tabular}

Fuente: elaboración propia

Las historias del éxito adquirieron un carácter especial cuando los medios de comunicación presentaron el rostro del salvadoreño que, gracias a las remesas, se convirtió en un "embajador" que defiende la causa de la migración: el presidente Elías Antonio Saca completó sus estudios gracias a las remesas que envió su hermano, quien se ganó la vida "lavando platos y pisos, manejando buses hasta que logró convertirse en médico internista" (LPG, 20/08/04).

Al mostrar a los migrantes exitosos, la prensa también retomó aquellas actividades que los migrantes han realizado en el extranjero. La vida cotidiana tiene matices, pero los salvadoreños han celebrado "la bajada" de su patrono, El Salvador del Mundo, en los Ángeles (LPG, 09/08/00), Panamá (LPG, 24/08/00), Montreal (LPG, 24/08/00), México (EDH, 02/08/90), Australia (LPG, 07/08/05), Suecia (LPG, 04/08/05); o el Carnaval de San Miguel en Houston que en 1990 celebró su octava edición (LPG, 09/12/90). Muchos de ellos empiezan a volver al país para las fiestas. Primero en diciembre y luego para cada fiesta en la que es posible volver. Estas noticias muestran que, cada vez más, los salvadoreños mantienen prácticas transnacionales, desterritorializadas (García Canclini, 2001), son aquí y allá. La prensa documenta procesos de sustitución de un sentido, un valor o una norma por otro distinto de la nueva cultura a la que los salvadoreños se han enfrentado. Documenta procesos de mantenimiento del significado, o de recreación y resignificación. También momentos de sincretismo de los cuales surge una propuesta de identidad nueva que toma de todas partes, pero que es novedosa y distinta del resto de vivencias culturales (Zapata, 2003). Son 69 las noticias de la muestra que recogen estas historias.

En 1985, la prensa informó que "[eligieron] a la señorita El Salvador en Los Ángeles”, que este concurso se inició desde hace cuatro años, es decir, desde 1981, y que se buscó mantener unida a la comunidad de salvadoreños de la zona que ya para esa fecha sobrepasaba los cien mil (EDH, 12/08/85). La comida típica empezó a ser exportada: "Welcome, pupusas y yuca frita Made in El Salvador" (LPG, 03/04/00). La prensa escrita constató que "en cualquier lugar donde haya 'guanacos', generalmente cerca hay una venta de comida típica salvadoreña, propiedad de un compatriota” (LPG, 03/04/00). 
En la construcción periodística de este anclaje con la vida cotidiana, destacó en la muestra la función de enlace que los medios facilitaron a partir del año 2000. Varias familias logran reunir de nuevo a sus seres queridos y otros más aprovecharon el espacio brindado por los medios para enviar mensajes y fotografías a sus conocidos en El Salvador. La agenda mediática sobre el tema de la migración posibilitó, en alguna medida, que los ciudadanos, los lectores, se apropiaran de espacios en los medios y pudieran contar sus historias en primera persona, sin la mediación del profesional que, desde su propio estilo, entreteje muchas veces los relatos.

\section{3.d. Lo social: el éxodo hacia la tierra prometida}

El éxodo es salida, marcha, emigración de una comunidad o un grupo de personas, explica el Diccionario de la Lengua Española (RAE, 2005). En la muestra, la prensa escrita ha presentado este éxodo con un cierto carácter religioso de ese pueblo que marcha hacia la tierra prometida. Una de las grandes preocupaciones sobre el tema de la migración pasa por la crónica del difícil trayecto que siguen los migrantes. En esta temática, el relato de la prensa escrita retoma un estilo dramático, una narrativa donde el héroe o la heroína ${ }^{8}$ se enfrentará a su destino y podrá evadirlo. Contradictoria. Difícil. Dura. Inacabada. La narración es la historia de aquel que se aventura en la ardua prueba. Si logra sortear todos los obstáculos obtendrá la recompensa de la "tierra prometida” (EDH, 02/05/05). Pero para alcanzar su objeto de deseo, nuestro héroe o nuestra heroína deberá enfrentarse a los malvados intereses de los coyotes, derrotar el hambre, el abrasante calor del desierto, la implacable "migra" y los recientes patrulleros.
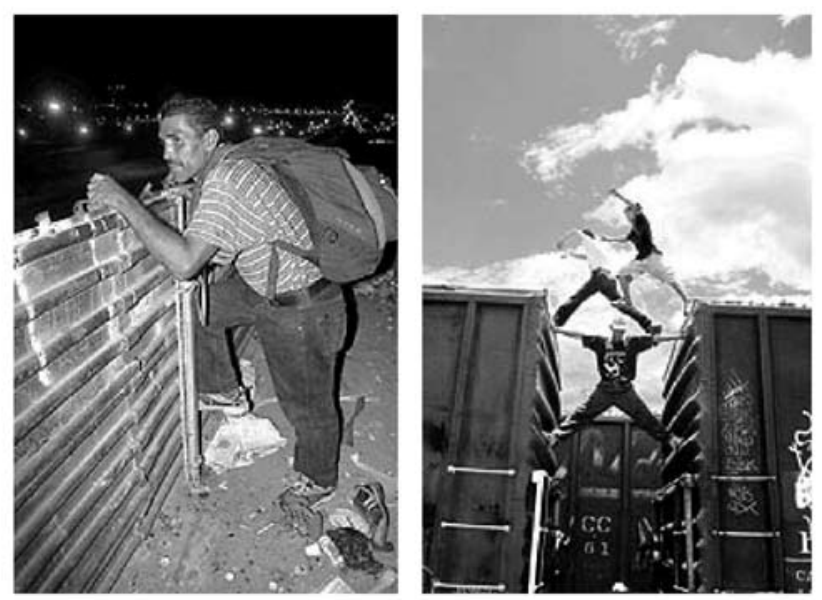

Ilustración 2. Fotos de EDH. Septiembre de 2004.

Aquí los “mojados” pernoctan en pensiones improvisadas, en donde en cada cuarto duermen hasta veinte personas por una tarifa de 50 pesos. Para evadir la estrecha vigilancia migratoria norteamericana, caminan jornadas de hasta 36 horas por la zona desértica hasta llegar a Tucson, Arizona, que se localiza a 68 millas del rancho La Sierrita. El último punto antes de ingresar 
a la “tierra prometida”. La travesía es un sorteo con la muerte porque en estas tierras abundan víboras, alimañas y... asaltantes que se cubren el rostro con gorros pasamontañas. ${ }^{9}$

Como el cuadro 5 presenta, las noticias sobre esta temática aumentan en cada año estudiado. En estas notas los personajes suelen aparecer de la misma manera, sus variaciones son mínimas a lo largo de la muestra. Desde 1985, el coyote es presentado como delincuente, se hace un llamado a la comunidad para que lo denuncie y se asocia el término coyote con el de estafador.

Cuadro 5: Noticias sobre la ruta del migrante, el coyote, los mojados

\begin{tabular}{|c|c|c|c|c|c|}
\hline & LPG & EDH & EM & CL & Total por año \\
\hline 1985 & 2 & 2 & 0 & 0 & 4 \\
\hline 1990 & 1 & 2 & 2 & 0 & 5 \\
\hline 1995 & 9 & 0 & 0 & 1 & 10 \\
\hline 2000 & 15 & 10 & 1 & 0 & 26 \\
\hline 2004 & 34 & 44 & 4 & 5 & 87 \\
\hline Total & 61 & 58 & 7 & 6 & 132 \\
\hline
\end{tabular}

Fuente: elaboración propia

La figura del coyote se complejiza en la información de los siguientes años. Por un lado se mantiene la imagen del estafador que muchas veces deja a las personas engañadas a medio camino o les cobra más de lo acordado. Pero poco después, ya en 1990, el crimen se agrava, como lo muestra un titular de La Prensa Gráfica que habla de "tráfico de menores secuestrados”. El coyote no sólo engaña a los ciudadanos, sino que se ensaña particularmente con aquellos que son el futuro de la sociedad y que no pueden protegerse del engaño. Posteriormente, ya en el año 2000, en la muestra aparecerá además como un secuestrador que pedirá rescate a las familias de los que se aventuran en el viaje. En esta temática es importante hacer notar que la población salvadoreña parece tomar distancia del discurso hegemónico pues, como lo muestra la encuesta reciente de LPG Datos, cinco de cada diez salvadoreños no está de acuerdo en castigar con la cárcel a las personas que se dedican a llevar a otras a Estados Unidos por vías ilegales (LPG, 06/03/05).

En 1995 las noticias recogieron la preocupación por la deportación masiva de los salvadoreños. Este tema se relacionó mucho con la preocupación por la deportación de criminales y pandilleros que se trabajó en la primera temática.

Ya para 2000 y 2004, la cantidad de noticias sobre este tema, en la muestra, fue mucho mayor. La diversidad de temáticas que se trabajaron varió mucho más. Los titulares dieron cuenta de ello. Se dio paso a historias personales: "Un día en la vida de la heroína" (LPG, 06/04/04). Se presentaron intentos fallidos que tuvieron como consecuencia la mutilación o la muerte de las víctimas: "Mueren cuatro compatriotas" (EM, 11/08/04) y se discutió la 
forma en que estos salvadoreños volverían al país. La historia de vida apareció como el género más usual y también aquellas historias con "función social", donde se solicitó a los lectores ayuda para los casos más impactantes.

En estas historias se hizo énfasis en la condición de pobreza de los migrantes, pero sin problematizar esta categoría, más bien mostrándola como un elemento más entre los atributos de las personas trabajadoras que buscaron salir adelante. El tono de varias de estas historias es trágico: "Queríamos ayudar a la familia... pero no se pudo" (LPG, 18/08/04). En algunas notas se encontraron historias que enfatizan la posibilidad de lograr "el sueño americano" y que alientan a continuar la ruta del migrante. Esto se ilustra en una nota que publicó el Diario CoLatino: "Insólito: liberan a salvadoreños ilegales". En la noticia se relata cómo, tras una persecución, la policía capturó a diez salvadoreños. Fueron remitidos a las autoridades de migración para su deportación, pero éstas tenían tanto trabajo que la policía terminó dejando a los detenidos en libertad. "Los salvadoreños arrestados pudieron seguir su camino... Qué suerte... tenían que ser salvadoreños... Dios estaba con ellos" (CL, 06/12/04). El elemento religioso presente en la cultura popular fue reforzado por este tratamiento periodístico que hizo ver al migrante que logró pasar esta prueba como alguien que tenía a Dios de ayudante en su travesía.

Dentro de la temática social, las historias de vida abundan mucho más que las discusiones sobre los derechos que los migrantes tienen. Antes de ser sujeto de derechos, el migrante ha sido protagonista de relatos.

\section{Ventana a los lectores}

Hastaahora he trabajado la construcción discursiva desdelaprensa, desde estemedio impreso salvadoreño. Sin embargo, las teorías sobre comunicación nos recuerdan que un mensaje no necesariamente es entendido y representado de la manera como el emisor del mensaje, en este caso el periodista, quiso que éste fuera imaginado. En 1973, Stuart Hall planteó ya un modelo de codificación-decodificación de mensajes que rechazaba el determinismo con el que las primeras teorías plantearon la recepción. Sostuvo que las audiencias se apropian de los mensajes de manera activa y dialéctica, aunque planteó como muy relevante el papel que la clase social ejercía en dichas interpretaciones. En la actualidad, los teóricos y estudiosos hablan de las mediaciones culturales que nos determinan, momentos en los cuales recibimos el mensaje, contextos políticos en los que nos hemos construido como personas (Orozco, 2002). En muchos casos las matrices culturales de aquellos que reciben un texto harán posibles nuevas interpretaciones, énfasis no necesariamente buscados, distancia, en fin, negociaciones.

En los primeros estudios de audiencia que se han llevado a cabo en el país sobre este tema, se han encontrado negociaciones como las que Chartier (en Ceballos y Alba, 2003) mencionaba entre las representaciones propuestas por el discurso oficial, gubernamental y los medios de comunicación. Y en las impuestas desde los públicos existen matices y distancias que vienen de la vivencia cotidiana familiar sobre la migración y de otros discursos populares como el religioso, el de consumo musical, particularmente de corridos sobre migrantes y de hip-hop (Martel y Marroquín, 2003 y 2007). 
forma en que estos salvadoreños volverían al país. La historia de vida apareció como el género más usual y también aquellas historias con "función social", donde se solicitó a los lectores ayuda para los casos más impactantes.

En estas historias se hizo énfasis en la condición de pobreza de los migrantes, pero sin problematizar esta categoría, más bien mostrándola como un elemento más entre los atributos de las personas trabajadoras que buscaron salir adelante. El tono de varias de estas historias es trágico: "Queríamos ayudar a la familia... pero no se pudo" (LPG, 18/08/04). En algunas notas se encontraron historias que enfatizan la posibilidad de lograr "el sueño americano" y que alientan a continuar la ruta del migrante. Esto se ilustra en una nota que publicó el Diario CoLatino: "Insólito: liberan a salvadoreños ilegales". En la noticia se relata cómo, tras una persecución, la policía capturó a diez salvadoreños. Fueron remitidos a las autoridades de migración para su deportación, pero éstas tenían tanto trabajo que la policía terminó dejando a los detenidos en libertad. "Los salvadoreños arrestados pudieron seguir su camino... Qué suerte... tenían que ser salvadoreños... Dios estaba con ellos" (CL, 06/12/04). El elemento religioso presente en la cultura popular fue reforzado por este tratamiento periodístico que hizo ver al migrante que logró pasar esta prueba como alguien que tenía a Dios de ayudante en su travesía.

Dentro de la temática social, las historias de vida abundan mucho más que las discusiones sobre los derechos que los migrantes tienen. Antes de ser sujeto de derechos, el migrante ha sido protagonista de relatos.

\section{Ventana a los lectores}

Hastaahora he trabajado la construcción discursiva desdelaprensa, desde estemedio impreso salvadoreño. Sin embargo, las teorías sobre comunicación nos recuerdan que un mensaje no necesariamente es entendido y representado de la manera como el emisor del mensaje, en este caso el periodista, quiso que éste fuera imaginado. En 1973, Stuart Hall planteó ya un modelo de codificación-decodificación de mensajes que rechazaba el determinismo con el que las primeras teorías plantearon la recepción. Sostuvo que las audiencias se apropian de los mensajes de manera activa y dialéctica, aunque planteó como muy relevante el papel que la clase social ejercía en dichas interpretaciones. En la actualidad, los teóricos y estudiosos hablan de las mediaciones culturales que nos determinan, momentos en los cuales recibimos el mensaje, contextos políticos en los que nos hemos construido como personas (Orozco, 2002). En muchos casos las matrices culturales de aquellos que reciben un texto harán posibles nuevas interpretaciones, énfasis no necesariamente buscados, distancia, en fin, negociaciones.

En los primeros estudios de audiencia que se han llevado a cabo en el país sobre este tema, se han encontrado negociaciones como las que Chartier (en Ceballos y Alba, 2003) mencionaba entre las representaciones propuestas por el discurso oficial, gubernamental y los medios de comunicación. Y en las impuestas desde los públicos existen matices y distancias que vienen de la vivencia cotidiana familiar sobre la migración y de otros discursos populares como el religioso, el de consumo musical, particularmente de corridos sobre migrantes y de hip-hop (Martel y Marroquín, 2003 y 2007). 
¿Qué rescatan los lectores de los periódicos de las noticias sobre migración? ¿Qué opinan del tratamiento que sobre ello se hace? Dos son los discursos esenciales que los lectores, consecuentes con el esfuerzo de la prensa escrita, identifican una y otra vez en sus intervenciones: migrar es bueno, nos llevará al éxito y migrar es algo peligroso, puedo morir en el intento. Estos dos discursos se corresponden con las dos constantes que aparecen en la prensa escrita a lo largo de la muestra, por un lado la visión del salvadoreño que alcanza el éxito en el extranjero, y por otro, el discurso que cada vez crece más de los muchos peligros que el migrante encontrará en su travesía. Hay una toma de distancia clara entre la conformación del coyote como un personaje oscuro y la opinión de los lectores que piensan que el coyote no debería ser juzgado por las leyes salvadoreñas como delincuente, como lo muestra una encuesta de La Prensa Gráfica retomada en el Informe de Desarrollo Humano (PNUD, 2005).

Algunas personas tomarán distancia y se situarán de manera crítica ante el discurso que los periódicos salvadoreños ofrecen. Esto muestra que las y los salvadoreños no necesariamente creen todo lo que los medios de comunicación presentan. Muchas de las exageraciones (positivas o negativas) aquí documentadas, también son anotadas. Los lectores, en este sentido, son exigentes. El cuadro 6 recoge la postura crítica de algunos de los lectores entrevistados.

Cuadro 6. Sondeo: ¿Recuerda usted noticias sobre migración en el periódico? ¿qué le parece la manera como la prensa aborda el tema?

- Son noticias muy tristes, muy fuertes (hombre, 17 años, Chalatenango).

- Se exagera muchas veces... (mujer, 19 años, San Miguel).

- Creo que los medios tienen interés en que la gente se vaya (hombre, 45 años, San Miguel).

- Dicen que los emigrantes van a tener mejores condiciones allá; dicen que el gobierno está buscando eso para ellos. La gente compara la noticia con lo bueno y lo malo de irse del país (mujer, 59 años, Ahuachapán).

- Me imagino que jamás van a dar la verdad de lo que ha sucedido, sólo pasan lo que les interesa (hombre, 23 años, San Miguel).

- Son bastante conmovedores, el leer el periódico y saber que mucha gente, por alcanzar el sueño americano, pierden la vida (mujer, 18 años, San Miguel).

- Es un poco exagerado, a veces no presentan el lado malo y no ven el positivo (mujer, 19 años, Apopa).

- El tratamiento es muy bajo porque no aceptan que hoy por hoy, las remesas es el principal sostenimiento de nuestro país y no les dan el tratamiento a nuestros compatriotas que están allá como se les debería de dar (hombre, 20 años, La Unión).

- Siento que debieran haberlo hecho mejor porque considero que lo presentan como algo necesario para la gente, migrar para superarse, cuando tendríamos que tener las mismas oportunidades para todo (hom- 
bre, 41 años, Ahuachapán).

- Pues yo no sé si es por darle pánico a la gente o será cierto que los van a deportar, yo creo que es por darle temor a la gente (Mujer, 56 años, Meanguera).

- Pues lo que se ha estado viendo y escuchando es lo que les sucede a los que intentan irse, lo mucho que sufren. Y yo creo que presentar así las noticias ayuda mucho a que otros desistan de irse creyendo que allá está la superación, pues según cuentan los que se han ido, no es así (hombre, 54 años, Salcoatitán).

- Algunas veces está bien y otras no porque son noticias demasiado impresionantes (mujer, 42 años, Usulután).

- Sale que es bien duro cruzar. A veces salen programas donde le dicen a la gente cómo hacer para irse, pero es paja, sólo mojado se va uno (hombre, 38 años, Apopa).

Fuente: elaboración propia

Además de la constatación sobre el discurso de la prensa escrita, los instrumentos del análisis del discurso nos permiten buscar qué es lo que los textos nos presentan, tanto en su estructura superficial como en su estructura profunda.

$\mathrm{Al}$ analizar la estructura superficial de los discursos periodísticos, en un primer momento podemos evidenciar cómo los textos se presentan en forma de relato. El relato del migrante que pasará por distintas pruebas y peripecias. Como todo relato puede ser leído desde aquellos actores que lo protagonizan. El migrante, héroe, va en busca de la tierra prometida, su objeto de deseo. Pero este viaje de partida no es tan sencillo. Se lo pensará mucho, se resistirá a salir de su lugar de origen. Los discursos de los medios de comunicación y los testimonios de aquellos que ya hicieron el viaje le contarán que hay muchos peligros esperándolo, que en el camino enfrentará muchas pruebas. Sin embargo, el héroe conocerá a un mentor, una persona (o un mensaje) que le hará ver que es necesario partir y buscar una vida mejor. Nuestro héroe tendrá que abrirse camino, comprometerse, sacar sus papeles, un suéter, la botella de agua y su mochila, y con ello emprenderá el viaje.

Cuando el migrante cruza hacia el mundo especial se encontrará con dos situaciones básicas. Habrá pruebas, y si éstas son superadas, entonces este mundo espacial le mostrará sus secretos y obtendrá su recompensa. Hay, sin embargo, un bache en el relato de la prensa, que se comprueba cuando se profundiza con las y los salvadoreños que han vivido la migración de manera directa: que entre enfrentarse a sus peores temores y lograr ser recompensado pueden pasar muchos años. Prácticamente no se encuentran en las noticias trabajadas desde la muestra, relatos sobre lo difícil y duro que puede ser encontrar trabajo en Estados Unidos, los problemas que se pasan para lograr la legalización y lo que puede suceder al ser deportado. ${ }^{10}$ 
Este discurso ya ha sido anotado por otras investigaciones que trabajan sobre el tema. Se advierte sobre los peligros del camino pero se idealizan, 0 al menos se omiten, las dificultades que existen una vez que se ha llegado al mundo especial. Esta omisión y "maquillaje” de la realidad en Estados Unidos está retomada en los trabajos de Diana Santillán y Sarah Mahler. Según Mahler (1995), un salvadoreño recuerda que cuando era niño escuchaba los relatos del primer emigrante de Intipucá, que le contó a todo el mundo que el dinero literalmente estaba desparramado por las calles. Santillán (2005:117) cuenta el caso de un emigrante que había oído que los dólares estaban tirados en las calles y que "podían recogerse con la escoba”. Al no presentar de manera significativa una discusión sobre las dificultades de la vida en Estados Unidos, la prensa escrita salvadoreña contribuye a mantener esta visión idealizada.

Si la estructura superficial nos muestra un relato, la estructura profunda recogerá categorías que se oponen dentro de los discursos. Aún con su diversidad, las noticias sobre migración manejan los relatos dentro de dos binomios básicos: se tiene éxito al llegar a Estados Unidos y enviar luego remesas o se fracasa y se vuelve deportado (o incluso muerto); se hace una opción por el bien y se parte sacrificando la felicidad propia por la de los seres queridos o se vive desde el mal y se cede a las tentaciones del tráfico, el dinero, las pandillas. En este sentido, en el trasfondo del discurso de la prensa escrita, se muestran cuatro grandes categorías: el bien, el mal, el éxito y el fracaso.

No son estas categorías las únicas, leído este esquema desde otras coordenadas, desde otras oposiciones se resaltarán matices distintos y otras particularidades: riqueza y pobreza; identidad individual y colectiva; el ciudadano común y el pandillero; la nación frente a lo local, el pueblo de donde se sale con rostros concretos y calles conocidas; la vida que lucha frente a la muerte que espera en el aire del desierto.

La historia es dinámica y cualquier fotografía fija es sólo una instantánea. Este retrato del relato de la prensa carece de la movilidad del objeto que ya se ha movido de lugar en el tiempo transcurrido en revelar -todavía sin la rapidez de la tecnología digital- la imagen. Como se dijo anteriormente, este trabajo intenta ser una provocación, un mapa que ayude a leer el rumbo que hasta el momento han seguido los estudios.

\section{Primeras conclusiones}

El lenguaje tiene el poder de clasificar. Foucault (2004) insistirá en que las palabras muestran nuestras posibilidades y límites para pensar lo mismo y lo otro. Esto sucede en esta crónica que ha recorrido el discurso que la prensa escrita ha utilizado para nombrar la migración. En ella encontramos, como consecuencia de sus formas de nombrar, propuestas de identidad que adquieren una particular importancia en nuestra sociedad salvadoreña. Una sociedad que todavía no termina de acostumbrarse a escuchar la diversidad en sus discursos sociales y políticos. Como lo explica Rodrigo Alsina: "los medios de comunicación son uno de los principales, aunque no los únicos, instrumentos de construcción de imágenes de identidad y de alteridad. Pero en aquellos casos en que no hay otras fuentes de información (comunicación interpersonal, libros, etc.) su predominio es notorio” (2003:99). 
Una mujer salvadoreña, residente en Los Ángeles, sostuvo que sus sentimientos hacia su país eran contradictorios: "hay amor a mi patria, pero también hay mucho resentimiento, porque cuando mando los dólares soy hermana lejana, pero cuando deportan a mi hijo ahí ya no soy nada". Desde este recorrido por el discurso de los medios, es importante recordar que la comunicación no es sólo cuestión de conocimiento, sino también de re-conocimiento, de re-apropiación de la historia. La migración es una historia que exige ser narrada mostrando su complejidad.

Hay tres elementos que se encuentran repetidos en los relatos que la prensa salvadoreña ha privilegiado hasta hoy. Primero, la noticia que predomina suele ser informativa y el espacio que hasta ese momento se daba a otros géneros periodísticos como el reportaje, la crónica o el editorial ha sido muy poco. Segundo, se presenta una postura oficial y en muchos casos ambigua en relación con la migración: es una realidad que lleva al éxito, pero también a la muerte; es algo bueno, pero malo; es algo que puede llevar a un reconocimiento social importante, pero también al estigma de la delincuencia si se fracasa y se llega a la deportación. Tercero, las distintas narrativas utilizadas por la prensa escrita se encuentran en la base de un nuevo imaginario de nación del que habla el Informe de Desarrollo Humano 2005 y muchos otros investigadores.

El relato periodístico privilegia narrativas deterministas. Las personas no pueden escapar de su destino. Los malos serán siempre malos, los jóvenes de las pandillas no podrán huir de esta realidad, tampoco los mojados. Con culpa o sin ella, la suerte está dada de antemano. En este relato, las y los salvadoreños se vuelven héroes que luchan por obtener el favor de su dios en el largo éxodo a través del desierto. Esta narrativa recoge los fracasos, pero sobre todo "canta" los éxitos. Conlleva una visión positiva de la realidad migratoria. Al migrar, los salvadoreños pueden progresar y alcanzar la tierra prometida.

Como se mencionó, no se encontraron en la muestra notas que cuenten a los que quieren migrar cómo hay muchos que, aunque lleguen a la tierra prometida, no logran salir de la pobreza. Muy pocas noticias priorizaron una difusión de los derechos de los migrantes y casi ninguna de las noticias analizadas se detuvo a reflexionar sobre las medidas que el país toma con las personas que llegan al país de una manera ilegal. El periodismo ha contrastado muy poco la realidad que vivimos como país expulsor y receptor a un tiempo.

Hace falta que los medios analicen a profundidad el trabajo que hasta ahora se ha hecho sobre la migración y que se discuta más sobre este fenómeno. Pero no sólo el periodismo tiene retos y deudas pendientes con la sociedad salvadoreña. También la academia tiene mucho por hacer. Por un lado, continuar profundizando investigaciones rigurosas sobre lo que ha sucedido con las migraciones y poner estos hechos en perspectiva histórica. Se debe sistematizar la experiencia de los distintos estudios locales y ponerlos en un diálogo no sólo nacional, sino regional que permita obtener nuevas conclusiones. Se debe atender la migración en su compleja realidad que no se reduce sólo a la migración hacia Estados Unidos, y recordar que esta última difícilmente puede ser explicada sin dialogar con las dinámicas locales, la migración del campo a la ciudad y el papel protagónico que está jugando la migración hacia otros países como Italia. Por otro lado, es necesario visibilizar y discutir, desde las publicaciones teóricas, los distintos esfuerzos por profesionalizar el tratamiento 
de la migración que algunos medios de comunicación de la región están llevando a cabo. Es un desafío de la academia distinguir, dentro del discurso de los medios, a los distintos actores que se involucran en la producción de las noticias, y diferenciar el trabajo y los objetivos de los periodistas de la apuesta editorial de las industrias mediáticas desde las cuales trabajan. No es pues la idea, condenar el trabajo periodístico, sino servirse de estos nuevos sociólogos, para decirlo con Bauman (2006), y propiciar junto a ellos la reconciliación con una parte de la identidad salvadoreña, ésa que se ancla fuera de los veinte mil kilómetros que marcan nuestro territorio.

\section{Agradecimientos}

El presente texto fue elaborado gracias a la investigación "Exploración de los patrones culturales y las formas de comunicación surgidas por las migraciones” para el proyecto "Migraciones internacionales y transformaciones económicas, políticas y culturales en El Salvador" UCA-SKM. Una versión preliminar de este ensayo fue preparada y presentada para el capítulo "Migraciones y diversidad cultural: al encuentro de un nuevo nosotros" del Informe sobre Desarrollo Humano El Salvador 2005: Una mirada al nuevo nosotros. El impacto de las migraciones, PNUD, San Salvador, 2005. El presente estudio agradece a los lectores y periodistas de la prensa escrita salvadoreña, en particular a Margarita I. Funes: lectora, periodista y amiga desde siempre.

\section{Notas}

1 Algunos estudios del Instituto de Opinión Pública (IUDOP) de la UCA dan cuenta de ello, así como estudios que han observado la relación que existe entre percepción de la inseguridad, construcción de ciudadanías del miedo y discursos sobre violencia en los medios de comunicación (Martel, 2006; Vasilachis, 2004

2 Una buena recopilación sobre la discusión de los enfoques con los que se aborda la influencia sobre los medios de comunicación puede encontrarse en Eric Maigret (2005)

3 Los dos periódicos principales tienen cobertura nacional e incluso secciones especializadas para los distintos departamentos. Su tiraje no es algo que pueda confirmarse desde fuera, pero los investigadores hablan de 100,000 ejemplares al día, el número de lectores se multiplica por cinco en cada caso.

4 El sondeo se realizó con 80 personas que residian en los municipios de Salcoatitán en el departamento de Sonsonate, Meanguera en Morazán, Apopa en San Salvador, San Antonio de la Cruz en Chalatenango, y en las cabeceras de Ahuachapán, Usulután, La Unión y San Miguel. Las personas se encontraban en los parques y plazas públicas y ahí fueron entrevistadas, cuidando que hubiera diferenciación de sexo y edad.

5 El promedio de páginas de los periódicos varía de una temporada a otra y con los años, en algunos casos, el número ha aumentado. Este promedio no contempla los suplementos especiales que en la mayoría de los casos suelen ofrecerse los días lunes, viernes, sábado y domingo.

6 En la foto podemos ver a este "inconfundible miembro de las maras". Junto a la foto, la caricatura de La Prensa Gráfica.

7 La siguiente temática que aparece con un número alto de notas es la de los relatos sobre coyotes y migrantes, con 132 publicaciones, aún así, las historias sobre la "tierra prometida" están muy por debajo de las 227 de las historias de salvadoreños exitosos. Estos datos ilustran, con un nivel aceptable de significatividad, dónde se encuentran los énfasis en las notas periodísticas de estos años estudiados.

8 Los protagonistas de estos relatos serán tanto femeninos como masculinos, desde las primeras notas documentadas de la muestra en 1985.

9 El Diario de Hoy. Suplemento Vértice. El éxodo al norte. Caminos de dolor. 19 al 26 de septiembre de 2004.

10 Es importante recordar que estos relatos pueden haber cobrado protagonismo a raíz de los incidentes y las protestas recientes de 2006. Sin embargo, esta hipótesis tendría que ser parte de un estudio posterior. 


\section{Referencias bibliográficas}

ANDRADE-EEKHOFF, K. (2003) Mitos y realidades. El impacto económico de la migración en los hogares rurales. San Salvador: FLACSO.

BAUMAN, Z. (2006, 15 de febrero) "Tenemos que pasar de la tolerancia a la solidaridad". En La Nación. Argentina. Pág. 1.

CEBALLOS, M. \& ALBA, G. (2003) "Viaje por el concepto de representación”. Signo y pensamiento. 22 (43). Págs 11 - 22.

CRUZ, M. \& SANTACRUZ, M. (2005) La victimización y la percepción de la seguridad ciudadana. San Salvador: Programa de las Naciones Unidas para el Desarrollo / Instituto de Opinión Pública de la UCA.

FOUCAULT, M. (2004) Las palabras y las cosas. México D.F.: Siglo XXI, (31ª ed.).

GARCÍA CANCLINI, N. (2001) Culturas híbridas. Estrategias para entrar y salir de la modernidad. México D.F.: Grijalbo, (2 ${ }^{\mathrm{a}}$ ed.).

GOFFMAN, I. (1970). Estigma. La identidad deteriorada. Buenos Aires: Amorrortu.

LATINOBARÓMETRO, (2006) Informe latinobarómetro 2006. Santiago de Chile: Corporación Latinobarómetro.

LUNGO, M. \& KANDEL, S. (2002). "Migración internacional, transnacionalismo y cambios socioculturales en Nueva Concepción”. ECA Estudios Centroamericanos, San Salvador, octubre (648), pp. 911-930.

MAHLER, S. J. (1995) American Dreaming. Immigrant Life on the Margins. New Jersey: Princeton University Press.

MAIGRET, E. (2005) Sociología de la comunicación y los medios. Bogotá: Fondo de Cultura Económica.

MARTEL, R. (2006) Las maras salvadoreñas: nuevas formas de espanto y de control social. Capítulo de libro. En prensa. México D.F.: FCE.

MARTEL, R. \& MARROQUÍN, A. (2007) "Crónica de fronteras: la música popular y la identidad salvadoreña migrante”. En Revista Istmo. Revista Virtual de Estudios Culturales y Centroamericanos. (14). Enero - junio.

MARTEL, R. \& MARROQUÍN, A. (2003) "La construcción de "lo migrante" como elemento de la identidad salvadoreña: cultura oficial y cultura popular". En ECA Estudios Centroamericanos, San Salvador, nov.-dic. (661-662), pp. 1221-1232.

MARTÍN BARBERO, J. (1998) De los medios a las mediaciones. Comunicación, cultura y hegemonía. Bogotá: Convenio Andrés Bello, (5 ed.).

OROZCO, G. (2002) “Travesías de la recepción en América Latina”. En Guillermo Orozco (comp.) Recepción y mediaciones. Casos de investigación en América Latina. (págs. 15-23). Bogotá: Norma.

PROGRAMA DE LAS NACIONES UNIDAS PARA EL DESARROLLO (2005) Informe sobre Desarrollo Humano El Salvador 2005. Una mirada al nuevo nosotros. El impacto de las migraciones. PNUD: San Salvador.

REAL ACADEMIA ESPAÑOLA (2005) Diccionario de la Lengua Española. (22a ed. con avances de la $23^{\mathrm{a}}$ ed.) Disponible en: http://www.rae.es. Consultado: 5 de junio de 2006.

RODRIGO ALSINA, M. (2003) "Representación de la inmigración: el poder en la construcción de la alteridad”. En Signo y pensamiento. 22 (43). Págs 99 - 111.

SANTILLÁN, D. (2005) "Renegociar las identidades nacionales: los vínculos transnacionales, losdiscursosdelasdiásporasylascomunidadespanétnicas”.EnLatransnacionalización 
de la sociedad centroamericana: visiones a partir de la migración. San Salvador: FLACSO, Págs. 101- 138.

VASILACHIS, I. (2004). "El lenguaje de la violencia en los medios de comunicación. Las otras formas de ser de la violencia y la prensa escrita”. En Programa de las Naciones Unidas para el Desarrollo. Aportes para la convivencia y la seguridad ciudadana. (pp. 109161). San Salvador: PNUD / Programa sociedad sin violencia / PRODECA.

YÚDICE, G. (2006). “¿Una o varias identidades? Globalización, cultura y migraciones”. En Cultura latina en Estados Unidos. Nueva Sociedad (201). Enero / Febrero 2006. Págs. 106-116.

ZAPATA, J. (2003). Cambio socio-cultural en las migraciones transnacionales. Disponible en: http://www.imsersomigracion.upco.es/Documentos/Otros/Zapata.CULTURA\%20Y\% 20MIGRACI\%C3\%93N.doc. Consultado: 8 de agosto de 2005. 